\title{
Chemoradiation in Unresectable Biliary Tract Cancer: A Systematic Review
}

\author{
Bisello $\mathbf{S}^{1}$, Buwenge $\mathbf{M}^{1 *}$, Zamagni $\mathrm{A}^{1}$, Deodato $\mathrm{F}^{2}$, Macchia ${ }^{2}$, Arcelli $\mathrm{A}^{1}$, Cilla $\mathrm{S}^{3}$, Cammelli $\mathbf{S}^{1}$, Mattiucci $\mathrm{GC}^{4}$, Cellini $\mathrm{F}^{4}$ and Morganti $\mathbf{A G}^{1}$ \\ ${ }^{1}$ Department of Experimental, Diagnostic and Speciality Medicine (DIMES), University of Bologna, S. Orsola- Malpighi Hospital, Bologna, Italy \\ 2Radiotherapy Unit, Fondazione "Giovanni Paolo II", Catholic University of Sacred Heart, Campobasso, Italy \\ ${ }^{3}$ Medical Physic Unit, Fondazione "Giovanni Paolo II", Catholic University of Sacred Heart, Campobasso, Italy \\ ${ }^{4}$ Radiation Oncology Department, Università Cattolica del Sacro Cuore, Rome, Italy
}

\begin{abstract}
Aim: To present a systematic review on efficacy and toxicity of modern concurrent chemoradiation (CCRT) in unresectable biliary tract cancers (BTC).

Methods: A systematic review of literature published within the last ten years (1 January 2007-31 December 2017), based on PRISMA methodology and using PubMed electronic database was conducted. Only articles reporting patients' outcome in terms of toxicity and/or overall survival (OS) or progression-free survival (PFS) after CCRT, with or without other treatments, were analyzed. Only studies of patients with diagnosis of unresectable BTC, including intrahepatic, extrahepatic, and gallbladder neoplasm were considered.
\end{abstract}

Results: Six eligible studies were included reporting data on 195 patients. Median follow-up ranged between 9.4 and 27.7 months (median: 16 months). Four studies were prospective phase II trials and 2 had a retrospective design. Different external beam radiotherapy (EBRT) techniques and chemotherapy (CT) schedules were used while only in one study a brachytherapy boost was delivered. Grade $\geq 3$ acute toxicity (hematological or gastrointestinal) ranged between 0.0 and $55.6 \%$ (median: $37.0 \%$ ). One study reported $30.0 \%$ gastrointestinal grade $\geq 2$ late toxicity. PFS ranged between 6.8 and 10.5 months (median: 7.5 months) in 5 studies. OS ranged between 9.6 and 13.5 months (median: 13 months) in 5 studies.

Conclusion: CCRT remains a reasonable treatment option for locally advanced BTC, providing results comparable with the ones of standard CT, particularly in terms of OS. Considering the progressive advance of modern EBRT techniques, further improvement of these results can be expected. Therefore, clinical trials based on advanced radiotherapy techniques and new integrations of CCRT with systemic treatments are warranted.

Keywords: Radiotherapy; Chemoradiation; Biliary tract cancers; Cholangiocarcinoma; Systematic review

\section{Introduction}

Biliary tract cancers (BTC) are rare malignancies, representing less than $3 \%$ of all gastrointestinal cancers and $10-15 \%$ of all primary hepatobiliary cancers. They are classified as: i) intrahepatic cholangiocarcinoma (ICC), originating from biliary three epithelia inside the liver; ii) extrahepatic cholangiocarcinoma (ECC), originating outside the liver parenchyma and further divided into proximal (or Klatskin's tumor) and distal; iii) gallbladder (GB) cancers, originating from gallbladder neck or fundus [1].

Prognosis is dismal, with 5-year overall survival (OS) around 20$30 \%$ in patients with early stage disease [2]. Complete resection is the mainstay of operable BTC but most patients are not candidates for curative surgery [1]. In fact, BTC are often diagnosed in advanced stages due to the aggressive nature of these tumors and nonspecific symptoms. Local and distant failures are frequent thus justifying the use of adjuvant treatments [1], although standard postoperative strategies have not been clearly defined.

Concurrent chemoradiation (CCRT) has been tested as an adjuvant therapy to reduce the recurrence rates, and in unresectable patients for symptomatic control. There is no consensus on the standard multimodality treatment of unresectable BTC, although international guidelines consider CCRT as an option [2]. In fact, some studies reported symptomatic relief and improved local control (LC) and OS [3-6] after CCRT compared to supportive therapy alone.

The main limitation of CCRT in BTC is the presence of radiosensitive organs in the upper abdomen. The current technology progress allows better targeting of the tumor with reduced risk of severe side effects. However, no systematic reviews are available on the efficacy of CCRT in the management of unresectable disease. Particularly, reviews focused on the results of 'modern' CCRT are lacking. Therefore, aim of this study is to perform a systematic analysis on efficacy and toxicity of CCRT in the treatment of unresectable BTC, based on papers published in the last 10 years.

\section{Literature Search}

We searched for prospective or retrospective published studies enrolling patients with unresectable locally advanced BTC, including intrahepatic, extrahepatic, and gallbladder cancer. A bibliographic research was performed based on PubMed. The following search strategy was used: "biliary tract neoplasms" [MeSH Terms] or ("biliary" [All Fields] AND "tract" [All Fields] AND "neoplasms" [All Fields])

*Corresponding author: Buwenge M, Department of Experimental, Diagnostic and Specialty Medicine - DIMES, Radiation Oncology Center, University of Bologna, S. Orsola-Malpighi Hospital, Italy-40138, Bologna Italy, Tel: +39 0512143564; E-mail: mbuwenge@gmail.com

Received May 18, 2018; Accepted May 28, 2018; Published June 6, 2018

Citation: Bisello S, Buwenge M, Zamagni A, Deodato F, Macchia G, et al. (2018) Chemoradiation in Unresectable Biliary Tract Cancer: A Systematic Review. Hepatol Pancreat Sci 2: 113.

Copyright: ( 2018 Bisello S, et al. This is an open-access article distributed under the terms of the Creative Commons Attribution License, which permits unrestricted use, distribution, and reproduction in any medium, provided the original author and source are credited. 
or "biliary tract neoplasms" [All Fields] OR ("biliary" [All Fields] AND "cancer" [All Fields]) OR "biliary cancer" [All Fields]) AND ("radiotherapy" [Subheading] OR "radiotherapy" [All Fields] OR "chemoradiotherapy" [MeSH Terms]. The search was completed by evaluating two additional reviews by Mattiucci et al. [3] and Chopra et al. [4]. The search was limited to the last ten years (January 2007 to December 2017). Only articles in English language reporting outcomes after CCRT with or without further treatments as brachytherapy or maintenance chemotherapy (CT) in locally advanced BTC were included. Exclusion criteria was: enrollment of less than 10 patients, other tumors involved and not-differentiated results, metastatic patients, dose-escalation studies, case reports, protocols, and adjuvant or neoadjuvant CCRT. Articles selection and data collection were analyzed by two authors (SB, AZ) and potentially eligible studies were evaluated after reading the full text. Disagreements were resolved by a third author $(\mathrm{MB})$.

\section{Outcome measures}

The main outcome measure was OS and secondary outcome measures were acute and late toxicity, local control (LC), and Progression Free Survival (PFS).

\section{Results}

From the literature search as described above, 60 articles were identified from the database, and 15 papers were retrieved from other sources. Figure 1 describes the process of papers selection. After removal of duplicates, thorough screening at title and abstract level, 20 articles were selected for full text reading and only 6 were considered eligible for inclusion.

\section{Literature Review}

Baisden and colleagues performed a phase II study to test a multimodality approach of Tomotherapy based Intensity Modulated RT (IMRT), CT, and photodynamic therapy in 10 patients with

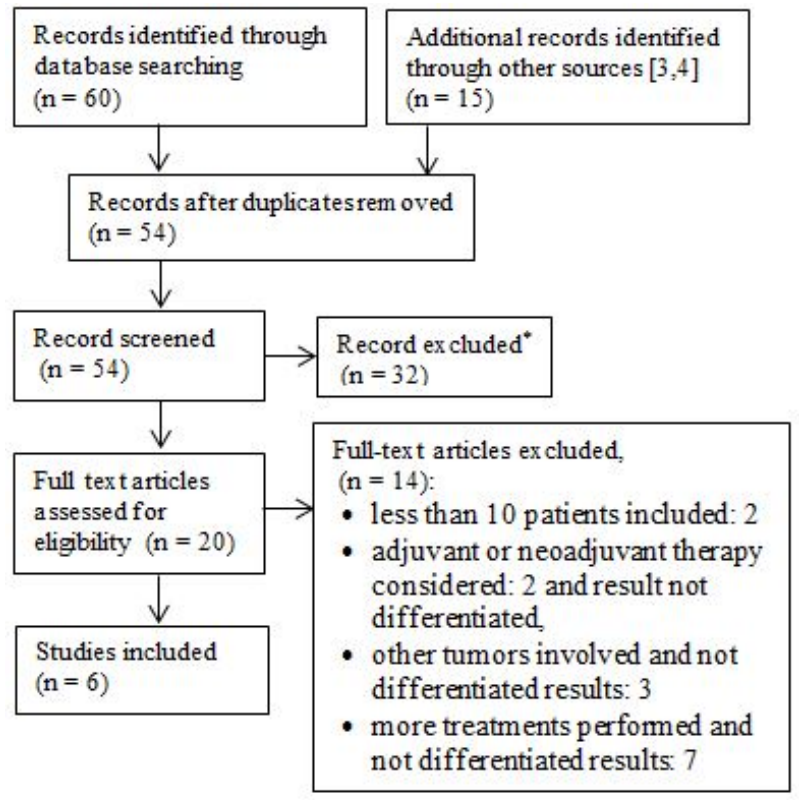

*Exclusion criteria reported in the full text.

Figure 1: Process of paper selection. unresectable hilar ECC. All patients received 50 Gy in 25 fractions plus concurrent capecitabine (Table 1). Acute and late toxicities were evaluated using the RTOG scale. No cases of grade $\geq 3$ acute and late grade $\geq 2$ toxicities were reported. Median OS and PFS were 13 and 10.5 months, respectively [7].

Phelip and coworkers reported the results of a phase II randomized study comparing CT versus combined CCRT in advanced BTC. In the CCRT cohort, 18 patients with locally advanced non-metastatic BTC (56\% ICC, $22 \%$ proximal ECC, $11 \%$ distal ECC and $11 \%$ GB) were enrolled. The RT dose was $50 \mathrm{~Gy}$ and concomitant CT was based on 5-Fluorouracil and Cisplatin. Acute and late toxicities were evaluated with CTCAEv2.0 scale. Grade $\geq 3$ acute and Grade $\geq 2$ toxicities were reported in $47 \%$ and $0.0 \%$ of patients, respectively. With a median follow up of 27.9 months, median OS, and PFS were 13.5 and 7.5 months respectively [8].

Autorino and colleagues, enrolled 27 patients with stage $\mathrm{T}_{2-4}$, inoperable ECC (66.6\% proximal and $33.4 \%$ distal) in a prospective phase II trial. Six patients received an intraluminal BT boost (15 Gy). RT dose was 50 Gy plus concurrent gemcitabine-based CT. Response was reported as stable disease (SD) in $81 \%$, and progressive disease (PD) in $15 \%$ of patients. Acute and late toxicity were evaluated with CTCAEv3.0 scale. Grade $\geq 3$ acute toxicity was recorded in $37 \%$ of patients. With a median follow up of 16 months, higher 2-year LC (53\% vs 25\%) was observed in patients receiving BT boost. Two-year OS was $27 \%$, with median OS being 21 months in the BT boost group versus 14 months in the group treated with CCRT alone [9].

Lee and coworkers enrolled 18 patients in a phase II prospective study. All patients had $\mathrm{T}_{2-4}$ unresectable non-metastatic BTC, $(33.3 \%$ proximal ECC, $22.2 \%$ distal ECC and $44.5 \%$ GB cancer). All patients received CCRT based on gemcitabine and cisplatin and RT dose was 45 Gy using 3D-RT. After CCRT, maintenance CT was administered until disease progression or uncontrolled toxicity. Reported tumor response, according to RECIST criteria, was $27.8 \%$ and $72.2 \% \mathrm{PR}$ and SD, respectively. Acute toxicity was evaluated with CTCAEv4.0 scale with $55.6 \%$ of patients experiencing grade $\geq 3$. Median OS and PFS were 9.6 and 6.8 months, respectively [10].

Seung and coworkers retrospectively reviewed 106 patients with $\mathrm{T}_{2-4}$ locally advanced, non-metastatic BTC, (39.6\% ICC, $29.2 \%$ ECC and $31.1 \%$ GB cancer). All patients received CCRT based on 5-FU and gemcitabine and total RT dose was $50.4 \mathrm{~Gy}$. Response was evaluated one month after CCRT according to RECIST criteria with $19.8 \% \mathrm{PR}$, $69.8 \%$ SD and $10.4 \%$ PD. All patients were evaluated for adverse effects with $31.1 \%$ of them experiencing grade $\geq 3$ acute toxicity. No cases of late grade $\geq 2$ toxicities were reported. Median OS and PFS were 42.6 and 29.9 weeks, respectively [11].

Chen and colleagues published a retrospective study on 34 patients with $\mathrm{T}_{2-4}$ unresectable hilar cholangiocarcinoma. Patients were treated with concurrent CCRT (16 patients) or RT alone (18 patients). CCRT was based on RT (55.1 Gy) and concurrent 5-FU. After CCRT, 4 patients received maintenance CT (gemcitabine and oxaliplatin, or 5-FU and oxaliplatin). With a median follow up of 16 months, median OS and PFS were 13.5 and 8.5 months, respectively [12].

\section{Analysis of Selected Studies}

In the six analyzed studies, data on 195 patients were reported. Median follow-up ranged between 9.4 and 27.9 months (median: 16 months). Four studies were prospective phase II trials and 2 were retrospective. All studies included patients diagnosed with unresectable 
Citation: Bisello S, Buwenge M, Zamagni A, Deodato F, Macchia G, et al. (2018) Chemoradiation in Unresectable Biliary Tract Cancer: A Systematic Review. Hepatol Pancreat Sci 2: 113.

Page 3 of 5

\begin{tabular}{|c|c|c|c|c|c|c|c|c|c|c|c|c|c|c|c|}
\hline $\begin{array}{c}\text { Reference } \\
\text { year }\end{array}$ & $\begin{array}{l}\text { Study } \\
\text { design }\end{array}$ & $\begin{array}{l}\mathbf{N}^{\mathbf{0}} \\
\text { pts }\end{array}$ & $\begin{array}{l}\text { Median } \\
\text { FUP } \\
\text { months } \\
\text { (range) }\end{array}$ & Diagnosis & Site \% & $\begin{array}{l}\text { Stage } \\
(\%)\end{array}$ & $\begin{array}{c}\text { CTV } \\
\text { definition }\end{array}$ & PTV & $\begin{array}{c}\text { Dose } \\
\text { (median) } \\
\text { Gy }\end{array}$ & $\begin{array}{c}\text { Treatmen } \\
t \%\end{array}$ & CT & $\begin{array}{c}\text { Technique } \\
\%\end{array}$ & $\begin{array}{c}\text { Tumor } \\
\text { response } \\
\% \\
\text { (criteria) }\end{array}$ & $\begin{array}{c}\text { Toxicity \% } \\
\text { (scale) }\end{array}$ & $\begin{array}{c}\text { Median } \\
\text { outcom } \\
\text { e } \\
\text { months } \\
\text { (range) }\end{array}$ \\
\hline $\begin{array}{l}\text { Baisden } \\
\text { et al. [7] }\end{array}$ & $\begin{array}{c}\text { Phase } \\
\text { II }\end{array}$ & 10 & $\mathrm{NR}$ & $\begin{array}{l}\text { Unresectab } \\
\text { le ECC }\end{array}$ & $\begin{array}{l}\text { Proximal } \\
\text { ECC: } 100\end{array}$ & $\mathrm{NR} \grave{t}$ & $\begin{array}{c}\mathrm{T}+\text { only } \\
\text { enlarged } \\
\text { pathologic } \\
\text { al LN }\end{array}$ & $\begin{array}{c}\text { GTV+10- } \\
15 \mathrm{~mm} \\
\text { radial, } \\
10-20 \mathrm{~mm} \\
\text { CC }\end{array}$ & 50 & $\begin{array}{l}\text { CCRT } \pm \\
\text { PTD: } \\
\text { PTD: } 60\end{array}$ & CAPE $3 \mathrm{~g}$ & IMRT & $\begin{array}{l}\mathrm{NR} \\
\text { (NR) }\end{array}$ & $\begin{array}{c}\text { Acute }(\mathrm{G} \geq 3) \\
0 \\
\text { late }(\mathrm{G} \geq 2) \\
\text { NR } \\
\text { (RTOG) }\end{array}$ & $\begin{array}{l}\text { OS: } 13 \text {; } \\
\text { PFS: } \\
10.5 ; \\
\text { LC: NR }\end{array}$ \\
\hline $\begin{array}{c}\text { Phelip } \\
\text { et al. [8] }\end{array}$ & $\begin{array}{c}\text { Phase } \\
\text { II }\end{array}$ & 18 & $\begin{array}{c}27.9( \pm \\
2.8)^{*}\end{array}$ & $\begin{array}{c}\text { LA non } \\
\text { metastatic }\end{array}$ & $\begin{array}{c}\text { ICC: } 56.0 ; \\
\text { proximal } \\
\text { ECC: } 22.0 \text {; } \\
\text { distal } \\
\text { ECC: } 11.0 \text {; } \\
\text { GB: } 11\end{array}$ & NR & $\mathrm{GTV}+\mathrm{N}$ & $\begin{array}{c}\text { CTV } \\
(\mathrm{T}+\text { nodes }) \\
+2 \mathrm{~cm}\end{array}$ & 50 & $\begin{array}{l}\text { CCRT: } \\
\text { CT: } 100\end{array}$ & $\begin{array}{c}5 \mathrm{FU} 300 \\
\mathrm{mg} / \mathrm{m}^{2} / \mathrm{die} \\
+\mathrm{CIS} 80 \\
\mathrm{mg} / \mathrm{m}^{2} / \mathrm{mo} \\
\mathrm{nth}\end{array}$ & CRT-3D & $\begin{array}{c}\mathrm{NR} \\
\text { (RECIST } \\
1.0)\end{array}$ & $\begin{array}{c}\text { Acute }(\mathrm{G} \geq 3) \text { : } \\
47.0 \\
\text { late }(\mathrm{G} \geq 2) \\
\mathrm{NR} \\
\text { (CTCAEv2.0) }\end{array}$ & $\begin{array}{c}\text { OS: } \\
13.5 ; \\
\text { PFS: } \\
7.5 ; \\
\text { LC: NR }\end{array}$ \\
\hline $\begin{array}{c}\text { Autorino } \\
\text { et al. [9] }\end{array}$ & $\begin{array}{c}\text { Phase } \\
\text { II }\end{array}$ & 27 & $\begin{array}{c}16 \\
(3-52)\end{array}$ & $\begin{array}{l}\text { Unresectab } \\
\text { le ECC }\end{array}$ & $\begin{array}{c}\text { Proximal: } \\
66.6 ; \\
\text { distal: } 33.4\end{array}$ & $\begin{array}{l}\text { T2:19.2; } \\
\text { T3:38.4; } \\
\text { T4:42.4; } \\
\mathrm{N}+: 42.4\end{array}$ & NR & NR & $\begin{array}{c}50.0 \\
\text { BT: } 15\end{array}$ & $\begin{array}{c}\text { CCRT: } 74 \\
\text { CCRT } \pm \\
\text { BT: } 22.3 \\
\text { RT: } 3.7\end{array}$ & $\begin{array}{c}\text { GEM } \\
1000 \\
\mathrm{mg} / \mathrm{m}^{2} / \text { we } \\
\text { ekly }\end{array}$ & CRT-3D & $\begin{array}{l}\text { SD: } 81.0 \\
\text { PD: } 15.0 ; \\
\text { NE: } 4 \\
\text { (NR) }\end{array}$ & $\begin{array}{c}\text { Acute }(\mathrm{G} \geq 3) \text { : } \\
37.0 \\
\text { late }(\mathrm{G} \geq 2) \\
\mathrm{NR} \\
(\text { CTCAEv2.0) }\end{array}$ & $\begin{array}{c}\text { OS: } \\
27.0 \% \\
\text { PFS: } \\
\text { NR; } \\
\text { LC: } \\
29.0 \%\end{array}$ \\
\hline $\begin{array}{c}\text { Lee } \\
\text { et al. [10] }\end{array}$ & $\begin{array}{l}\text { Phase } \\
\text { II }\end{array}$ & 18 & NR & $\begin{array}{l}\text { Unresectab } \\
\text { le non- } \\
\text { metastatic } \\
\text { BTC }\end{array}$ & $\begin{array}{c}\text { Proximal } \\
\text { ECC: } 33.3 \\
\text { distal } \\
\text { ECC: } 22.2 \\
\text { GB: } 44.5\end{array}$ & $\begin{array}{c}\text { T2: } 22.2 \\
\text { T3: } 72.2 \\
\text { T4: } 5.6\end{array}$ & $\mathrm{GTV}+\mathrm{N}$ & $\begin{array}{c}\mathrm{CTV}+5 \\
\mathrm{~mm}\end{array}$ & 45 & $\begin{array}{c}\text { CCRT+C } \\
\text { T } 100\end{array}$ & $\begin{array}{c}\text { GEM } \\
1000 \\
\mathrm{mg} / \mathrm{m}^{2} / \mathrm{we} \\
\mathrm{ekly}+ \\
\mathrm{CIS} 70 \\
\mathrm{mg} / \mathrm{m}^{2} / \mathrm{mo} \\
\mathrm{nth}\end{array}$ & CRT-3D & $\begin{array}{c}\text { PR: } 27.8 \\
\text { SD: } 72.2 \\
\text { (RECIST) }\end{array}$ & $\begin{array}{c}\text { Acute }(\mathrm{G} \geq 3) \text { : } \\
55.6 \\
\text { late }(\mathrm{G} \geq 2) \text { : } \\
\text { NR } \\
\text { (CTCAEv4.0) }\end{array}$ & $\begin{array}{l}\text { OS: } 9.6 ; \\
\text { PFS: } 6.8\end{array}$ \\
\hline $\begin{array}{c}\text { Seung } \\
\text { et al. [11] }\end{array}$ & $\begin{array}{c}\text { Retros } \\
\text { pec }\end{array}$ & 106 & NR & $\begin{array}{c}\text { LA } \\
\text { non- } \\
\text { metastatic } \\
\text { BTC }\end{array}$ & $\begin{array}{c}\text { ICC: } 39.6 \\
\text { ECC: } 29.2 \\
\text { GB: } 31.1\end{array}$ & $\begin{array}{r}\text { T2: } 11.3 \\
\text { T3: } 67.0 \\
\text { T4: } 21.7 \\
\mathrm{~N}+: 80.2\end{array}$ & NR & NR & 50.4 & $\begin{array}{c}\text { CCRT } \\
100\end{array}$ & $\begin{array}{c}5 \mathrm{FU} 1000 \\
\mathrm{mg} / \mathrm{m}^{2} / \mathrm{di} \\
+\mathrm{GEM} \\
1000 \\
\mathrm{mg} / \mathrm{m}^{2} / \mathrm{die}\end{array}$ & CRT-3D & $\begin{array}{l}\text { PR: } 19.8 \\
\text { SD: } 69.8 \\
\text { PD: } 10.4 \\
\text { (RECIST) }\end{array}$ & $\begin{array}{c}\text { Acute }(\mathrm{G} \geq 3) \\
31.1 \\
\text { late }(\mathrm{G} \geq 2) \\
\mathrm{NR}\end{array}$ & $\begin{array}{c}\text { OS: } \\
10.7 ; \\
\text { PFS: } \\
7.5 ; \\
\text { LC: NR }\end{array}$ \\
\hline $\begin{array}{c}\text { Chen } \\
\text { et al. [12] }\end{array}$ & $\begin{array}{c}\text { Retros } \\
\text { pec }\end{array}$ & 16 & $\begin{array}{c}9.4 \\
(2.4- \\
47.4)\end{array}$ & $\begin{array}{l}\text { unresectab } \\
\text { le HCCA }\end{array}$ & $\begin{array}{l}\text { Proximal } \\
\text { ECC: } 100\end{array}$ & $\begin{array}{l}\text { T2: } 31 \\
\text { T3: } 38 \\
\text { T4: } 31 \\
\text { N+: } 50 \\
\end{array}$ & $\begin{array}{c}\mathrm{GTV}+0.5 \\
\mathrm{~mm}\end{array}$ & $\mathrm{CTV}+1 \mathrm{~cm}$ & $\begin{array}{l}55.1 \pm \\
5.4^{*}\end{array}$ & $\begin{array}{c}\text { CCRT } \\
100 \\
\text { CCRT+C } \\
\text { T } 25 \\
\end{array}$ & $\begin{array}{c}5 \mathrm{FU} 500 \\
\mathrm{mg} / \mathrm{m}^{2} / \mathrm{die}\end{array}$ & CRT-3D & NR & $\begin{array}{c}\mathrm{NR} \\
\text { (CTCAEv3.0) }\end{array}$ & $\begin{array}{c}\text { OS: } \\
13.5 \\
\text { PFS: } 8.5 \\
\text { LC: NR }\end{array}$ \\
\hline
\end{tabular}

Note: BT: Brachytherapy; BTC: Biliary Tract Cancer; CAPE: Capecitabine; CC: Craniocaudal; CIS: Cisplatin; CR: Complete Response; CRT-3D: Conformal Three-dimensional Radiotherapy; CT: Chemotherapy; CTCAE: Common Terminology Criteria for Adverse Event; CTV: Clinical Target Volume; ECC: Extrahepatic Cholangiocarcinoma GEM: Gemcitabine; GTV: Gross Tumor Volume; HCCA: Hilar Cholangiocarcinoma; ICC: Intrahepatic Cholangiocarcinoma; IMRT: Intensity Modulated Radiotherapy; LA: Locally Advanced; NCI-CTC : National Cancer Institute-Common Terminology Criteria; ND: Not Determined; No. pts: Number of Patients; NR: Not Reported; OS: Overall Survival; PD: Progression Disease; PFS: Progression Free Survival; PR: Partial Response; Prospect: Prospective; PTD: Photodynamic Therapy; PTV: Planning Target Volume; Retrospect: Retrospective; CCRT: Chemo-Radiotherapy; RTOG: Radiation Oncology Toxicity Grading; SD: Stable Disease; SBRT: Stereotactic Body Radiation Therapy; 5FU: 5-Fluorouracil; $\ddagger$ stage described as Bismuth type, according to definition of tumor extension; *average \pm standard deviation reported in this work; ${ }^{*} 2$-year overall survival

Table 1: Study characteristic

or locally advanced BTC, including intrahepatic, extrahepatic (proximal and distal) and GB neoplasm. Tumor sites in all studies were reported [7-12]. In 3 studies [8,10,11] GB cancers were also included while in 2 studies, all enrolled patients had perihilar CC $[7,12]$.

All studies were based on combined CCRT [7-12]. However, in one trial [9] a BT boost (15 Gy) was delivered in some patients, in another study [7] Photodynamic therapy (PTD) was combined with CCRT, and in 2 studies $[10,12]$ maintenance CT was prescribed after CCRT. RT technique was 3D conformal in 5 studies [8-12] and IMRT (tomotherapy) in one [7]. Median prescribed external RT dose ranged from 30 to 55.1 Gy with conventional fractionation. Planning Target Volume (PTV) definition was not specified in 2 studies [9,11]. In three studies $[7,8,10]$ the clinical target volumes (CTV) was defined as GTV plus regional nodes, and in one study [12] as GTV plus $0.5 \mathrm{~cm}$. The CTV to PTV margin was $5-10 \mathrm{~mm}$ in 2 studies $[7,10]$ and $10-20 \mathrm{~mm}$ in other 2 studies $[8,12]$ while in one study the PTV was defined as GTV plus $10-15 \mathrm{~mm}$ radially and $10-20 \mathrm{~mm}$ craniocaudally [7].

Concurrent CT schedules were different in all the 6 studies: Capecitabine $3 \mathrm{~g} / \mathrm{die}$ [7], Fluorouracil $\left(300 \mathrm{mg} / \mathrm{m}^{2} / \mathrm{die}\right)$ plus Cisplatin (80 $\left.\mathrm{mg} / \mathrm{m}^{2} / \mathrm{month}\right)$ [8], and Gemcitabine $\left(1000 \mathrm{mg} / \mathrm{m}^{2} /\right.$ weekly) [9], Gemcitabine (1000 mg/m²/weekly)+Cisplatin (70 mg/m²/weekly) [10], Fluorouracil $\left(1000 \mathrm{mg} / \mathrm{m}^{2} /\right.$ die $)+$ Gemcitabine $\left(1000 \mathrm{mg} / \mathrm{m}^{2} / \mathrm{die}\right)[11]$ and Fluorouracil $\left(500 \mathrm{mg} / \mathrm{m}^{2} / \mathrm{die}\right)$ [12].

Tumor Response evaluation was reported in 3 studies, using the RECIST criteria in 2 studies [9-11]. PR was recorded in 2 studies with $19.8 \%$ and $27.8 \%$ rates [11]. SD was reported in 3 studies and ranged from 69.8 to $81.0 \%$ (median $72.2 \%$ ) [9-11]. PD was reported in 2 studies with $10.4 \%$ and $15.0 \%$ rates $[9,11]$. Tumor response evaluation timing was reported in 2 studies being one month after CCRT in both series $[10,11]$.

Toxicity evaluation was performed in 4 studies using RTOG scale, CTCAEv2.0 and CTCAEv4.0 [7-10]. One study [11] reported toxicity without specifying the evaluation scale. Grade $\geq 3$ acute hematological and/or gastrointestinal toxicity were recorded. Grade $\geq 3$ acute toxicity ranged between 0.0-55.6\% (median: 37.0\%).

Actuarial 2-year LC was reported in one study being 29.0\% [9]. PFS ranged between 6.8 and 10.5 months (median: 7.5 months) in 5 studies. OS ranged between 9.6 and 13.5 months (median: 13 months) in 5 studies $[7,8,10-12]$. One study reported actuarial 2 -year OS as $27.0 \%$ [9].

\section{Discussion}

To the best of our knowledge, this is the first systematic review on combined CCRT in unresectable, locally advanced BTC published in the last decade. Main results of our analysis are the following: 13 months median OS, 7.5 months median PFS, 37.0\% median Grade $\geq 3$ acute toxicity, and late toxicity was not reported by any study.

This analysis presents obvious limitations. Only 6 trials were eligible and almost all studies enrolled small numbers of patients $(\leq$ 30), except for 1 retrospective study that analysed 106 patients [11]. Furthermore, the analysed studies were heterogeneous in terms of tumour characteristics, PTV definition, delivered dose, and concurrent CT.

Locally advanced unresectable disease is the most common presentation of BTC, and CT is considered the main treatment option. 
Kim et al. [13] reported 13.8 months OS in patients with locally advanced (non-metastatic) BTC who were treated with gemcitabine plus cisplatin. In the ABC- 02 trial, Valle and coworkers reported $70.7 \%$ Grade $\geq 3$ toxicity in patients treated with the same regimen, now considered as the standard treatment. Therefore, if we compare OS and toxicity of CCRT and CT, we could conclude that the results are very similar, despite the obvious limitation of indirect comparison. Moreover, the Score-Matched Analysis on 2996 patients with unresectable biliary and peri-ampullary cancer (1871 treated with CT and 1070 with CCRT), demonstrated an improved OS in the CCRT group (14.5 months $v s 12.6$ months).

However, the results of our analysis are somewhat disappointing. In fact, no clear improvements in terms of outcomes are evident, despite the recent evolution of RT techniques, compared to studies published in previous decades.

From some results published over 10 years ago, in the Morganti et al. [14] trial, 21.2 months median OS was reported after CCRT + BT in unresectable BTC patients. In an update of that experience, Deodato et al. [5] reported a median OS with and without BT boost of 22 and 13 months, respectively. Foo et al. [15] using two-dimensional RT technique plus ${ }^{192}$ Ir boost, reported $14.1 \% 5$-year OS. Finally, Brunner et al. [16], in a retrospective analysis on 98 patients treated with CCRT plus ${ }^{192} \mathrm{Ir}$ boost, reported 22.7 months OS.

These studies not only show the lack of improved results, despite improvements in imaging, RT techniques, and likely supportive therapies, but also highlight the positive role of BT boost [4,14-16]. Indirectly, this data would indicate a RT dose/outcome relationship. The review of Mattiucci et al. [3], including papers published between 1990 and 2011 that reported an improved LC by combining CCRT with intra-luminal BT in unresectable patients, seems to confirm this dose/ effect relationship.

The results of the series analyzed in this study are quite homogeneous in terms of response and survival. The only obvious difference concerns the Grade $\geq 3$ acute toxicity, which was $31.1 \%-55.6 \%$ in 4 studies [811], while in another study was $0 \%$ [7]. A possible explanation of this difference could be related to the use of 3D-RT in the first 4 studies and of IMRT in the last one.

New strategies as stereotactic RT in unresectable BTC have been recently evaluated with median PFS and OS of 10.5 and 15 months, respectively [17-23]. These results seem at least similar to those obtained with CCRT, even if direct comparisons between the two techniques are lacking. However, almost in selected cases, stereotactic RT could be considered as an alternative treatment due to i) potentially higher biologically effective dose, ii) increased patient convenience, and iii) minimal interference with the delivery of CT.

Another interesting option in unresectable BTC could be the use of CCRT as preoperative treatment with the aim of tumor down-staging followed by surgery. Using this strategy, Cho et al. [24] reported $50.0 \%$ 3 -year OS in 68 patients with unresectable BTC. Based on these results, patients treated with CCRT should be systematically re-evaluated for surgical resection after a proper interval following combined treatment.

\section{Conclusion}

Our review did not show significant improvement compared to the older studies based on simpler RT techniques. Further innovative investigations should be performed based on the recent technological advancement of external beam RT and $\mathrm{BT}$ techniques and on the evidences on a dose-response relationship in CCRT treatments.
Moreover, new combined modality treatments with systemic treatments and/or surgery are to be tested. In general, the results on CCRT are almost comparable with the ones of $\mathrm{CT}$, and therefore this treatment should still be considered as a treatment options.

\section{Disclosure}

The author reports no conflicts of interest in this work.

\section{References}

1. Valle JM, Borbath I, Khan SA, Huguet F, Gruenber T, et al. (2016) Biliary cancer ESMO clinical practice guidelines for diagnosis, treatment and follow up. Ann Oncol 27: 28-37.

2. NCCN guideline (2018) Hepatobiliary Cancers.

3. Mattiucci GC, Autorino R, Agostino GR, Deodato F, Macchia G, et al. (2014) Chemoradiation and Brachitherapy in extrahepatic bile duct carcinoma. Crit Rev Oncol Hematol 90: 58-67.

4. Chopra S, Mathew AS, Engineer R, Shrivastava SK (2014) Positioning high-dose radiation in multidisciplinary management of unresectable cholangiocarcinomas: Review of current evidence. Indian J Gastroenterol 33: 401-407.

5. Deodato F, Clemente G, Mattiucci GC, Macchia G, Costamagna, G, et al (2006) Chemoradiation and brachytherapy in biliary tract carcinoma: long-term results. Int J Radiat Oncol Biol Phys 64: 483-488.

6. Ghafoori AP, Nelson JW, Willet CG, Chino JC, Tyler DS, et al. (2011) Radiotherapy in the treatment of patients with unresectable extrahepatic cholangiocarcinoma. Int J Radiat Oncol Biol Phys 8: 654-659.

7. Baisen JM, Kahaleh M, Weiss GR, Sanfey H, Moskaluk CA, et al. (2008) Multimodality treatment with helical tomotherapy intensity modulated radiotherapy, capecitabine, and photodynamic therapy is feasible and well tolerated in patients with hilar cholangiocarcinoma. Gastrointest Cancer Res 2: 219-224.

8. Phelip JM, Vendrely V, Rostain F, Subtil F, Jouve JL, et al. (2014) Gemcitabine plus cisplatin versus chemoradiotherapy in locally advanced biliary tract cancer Fédération Francophone de Cancérologie Digestive 9902 phase II randomized study. Eur J Cancer 50: 2975-2982.

9. Autorino R, Mattiucci GC, Ardito F, Balducci M, Deodato F, et al. (2016) Radiochemotherapy with Gemcitabine in Unresectable Extrahepatic Cholangiocarcinoma: Long-term result of a Phase II Study. Anticancer Res 36: 737-740.

10. Lee KJ, Yi SW, Cha J, Seong J, Bang S, et al. (2016) A pilot study of concurrent chemoradiotherapy with gemcitabine and cisplatin in patients with locally advanced biliary tract cancer. Cancer Chemother Pharmacol 78: 841-846.

11. Yi SW, Kang DR, Kim KS, Park MS, Seong J, et al. (2014) Efficacy of concurrent chemoradiotherapy with 5-fluorouracil or gemcitabine in locally advanced biliary tract cancer. Cancer Chemother Pharmacol 73: 191-198.

12. Chen SC, Chen MH, Li CP, Chen MH, Chang PM, et al. (2015) External bean radiation therapy with or without concurrent chemotherapy for patients with unresectable locally advanced hilar cholangiocarcinoma. Hepato Gastroenterol 62: $102-107$

13. Kim BJ, Hyung J, Yoo C, Kim KP, Park SJ, et al. (2017) Prognostic factors in patients with advanced biliary tract cancer treated with first-line gemcitabine plus cisplatin: retrospective analysis of 740 patients. Cancer Chemoter Pharmacol 80: 209-215.

14. Morganti AG, Trodella L, Valentini V, Montemaggi P, Costamagna G, et al (2000) Combined modality treatment in unresectable, extrahepatic biliary carcinoma. Int J Radiat Oncol 46: 913-919.

15. Foo ML, Gunderson LL, Bender CE, Buskirk SJ (1997) External radiation therapy and transcatheter iridium in the treatment of extrahepaticbile duct carcinoma. Int J Radiat Oncol Biol Phys 39: 929-935.

16. Brunner TB, Schwab D, Meyer T, Sauer R (2004) Chemoradiation may prolong survival of patients with non-bulky unresectable extrahepatic biliary carcinoma Strahlenther Onkol 180: 751-7.

17. Shen ZT, Zhou H, Li AM, Li B, Shen JS, et al. (2017) Clinical outcomes and prognostic factors of stereotactic body radiation therapy for intrahepatic cholangiocarcinoma. Oncotarget 8: 93541-93550. 
Citation: Bisello S, Buwenge M, Zamagni A, Deodato F, Macchia G, et al. (2018) Chemoradiation in Unresectable Biliary Tract Cancer: A Systematic Review. Hepatol Pancreat Sci 2: 113.

18. Sandler KA, Veruttipong D, Agopian VG, Finn RS, Hong JC, et al. (2016) Stereotactic Body Radiotherapy (SBRT) for Locally Advanced Extrahepatic and Intrahepatic Cholangiocarcinoma. Adv Radiat Oncol 1: 237-242.

19. Mahadevan A, Dagoglu N, Mancias J, Raven K, Khwaja K, et al. (2015) Stereotactic Body Radiotherapy (SBRT) for Intrahepatic and Hilar Cholangiocarcinoma. J Cancer 6: 1099-1104.

20. Jung DH, Kim MS, Cho CK, Yoo KJ, Jang WI, et al. (2014) Outcomes of stereotactic body radiotherapy for unresectable primary or recurrent cholangiocarcinoma. Radiat Oncol J 32: 163-169.

21. Ibarra RA, Rojas D, Snyder L, Yao M, Fabien J, et al. (2012) Multicenter results of stereotactic body radiotherapy (SBRT) for non-resectable primary liver tumors. Acta Oncol 51: 575-583.
22. Kopek N, Holt MI, Hansen AT, Høyer M (2010) Stereotactic body radiotherapy for unresectable cholangiocarcinoma. Radiother Oncol 94: 47-52.

23. Tse RV, Hawkins M, Lockwood G, Kim JJ, Cummings B, et al. (2008) Phase I study of individualized stereotactic body radiotherapy for hepatocellular carcinoma and intrahepatic cholangiocarcinoma. J Clin Oncol 26: 657-664.

24. Cho Y, Kim TH, Seong J (2017) Improved oncology outcome with chemoradiotherapy followed by surgery in unresectable intrahepatic cholangiocarcinoma. Strahlenther Onkol 193: 620-629 